\title{
Predictors for the prevalence of under-nutrition, wasting and stunting of 3 to 12 years school aged children in the Asella Luther Child Development Project - Oromiyaa, Ethiopia.
}

Elema TB*

Department of Food Science and PHT, College of Agriculture and Environmental Sciences, Arsi University, Asella, Ethiopia

\begin{abstract}
Background: Malnutrition remains a major public health problem in developing countries. In Oromia region prevalence of child malnutrition indicated that $29.1 \%$ with $6.6 \%$ severe underweight, $14.1 \%$ of the children are wasted $(3.5 \%$ severe wasting) and $53.6 \%$ of the children are stunted with $17.1 \%$ severe stunting. Primary school age is a dynamic period of physical and mental development. The Federal Democratic Republic of Ethiopia (FDRE) paid due attention to malnutrition, but still constant.
\end{abstract}

Objective: The objective of the research was to determine the prevalence of undernutrition; Wasting and Stunting for children registered in Lutheran project and associated factors.

Methods: Project based case studies of 384 children and cross sectional study design were applied to determine the magnitude of malnutrition using Semi-structured questionnaire, anthropometric measurements and clinical examination of 217 samples. Binary logistic regression was carried out, using Odds Ratio to determine the strength of predictors.

Results: From socio-demographic characteristics $61.28 \%$ of the children moderate while $5.98 \%$ of them were extremely strong academically. Clinical examination showed only $9.4 \%$ of was moderately malnourished. 70.94 to $100 \%$ of the children were not taken the diphtheria tetanus, influenza diseases and hepatitis A vaccination. Based on Weight for Age, Height for Age and Weight for Height; $23 \%$, children were severely undernutrition, $23 \%$ severely stunted and $16 \%$ severely wasted where $47 \%, 34 \%$ and $19 \%$ under a risk of undernutrition, stunting and wasting respectively. $60.68 \%$ of children were not received vitamin A regularly.

Conclusion: Children who's not completed Vitamin A Versus completed (AOR=1.298), completed vaccination $(\mathrm{AOR}=\mathbf{0 . 3 7 9})$, Female/male $(\mathrm{AOR}=\mathbf{2 . 5 3 3})$ underweight. The finding indicated that explanation of $\mathrm{Z}$-score is important that explaining the malnutrition status of the children. Maternal/guardians educational status was associated with children's underweight. Prevalence of malnutrition was occurred in less percent than the regional data. Breakfast is widely acknowledged to be the most important meal of the day and awareness creation also very important for the community to not miss breakfast possibly.

Keywords: Underweight (WFA), School-age children, Stunting (HFA), Wasting (WFH), School performance.

\section{Introduction}

Malnutrition continues to be a major public health problem in developing countries [1]. It is the most important risk factor for the burden of diseases. High malnutrition rates in the country pose a significant obstacle to achieving better child health outcomes [2]. In Ethiopia, child malnutrition is one of the most serious public health problem and the highest in the world. Nationally about $56 \%$ under a risk of stunting (38\% moderate and $18 \%$ severely stunted), $31 \%$ underweight and $23 \%$ children were wasted [3-5]. In Oromia region prevalence of child malnutrition indicated that $29.1 \%$ was underweight with $6.6 \%$ severe underweight, $14.1 \%$ of the children are wasted $(3.5 \%$ severe wasting) and $53.6 \%$ of the children are stunted with $17.1 \%$ severe stunting $[3,5]$. Beside that of the well-known 1 factors like poor diet and disease in which themselves caused by a set of underlying factors; household food security, maternal/ child caring practices and access to health services and healthy environment are the factors of malnutrition also influenced by the basic socio-economic and political conditions [4].

Malnutrition and school performance effects are interrelated. The development of any nation or community depends largely on the quality of education of such a nation. Primary school age is a dynamic period of physical growth as well as of mental development of the child [6]. It has been argued that health is an important factor for academic achievement at school and in higher education. Similarly, another review showed positive associations between parameters of health (e.g., school-based physical activities) and academic outcomes/performance [3]. 
Citation: Elema TB. Predictors for the prevalence of under-nutrition, wasting and stunting of 3 to 12 years school aged children in the Asella Luther Child Development Project - Oromiyaa, Ethiopia.. J Nutr Hum Health. 2018;2(2):1-10

Understanding the nature of the causal relationship between health and education is important to determine the exact relation between them. Conversely, most studies of the factors associated with students' educational attainment were mainly concerned with educational and/or demographic variables and did not concurrently explore the students' health-related parameters [7]. Several studies have documented the relationship between poor health, nutrition and school achievement. Low anthropometric measurements (height-for-age, weight-for height and head circumference) have been frequently associated with poor school outcomes $[3,8]$.

Lastly the government of Ethiopia also aimed to improve School nutrition program by starting school feeding practices for the future in order to reduce the risk of poverty and malnutrition. According to the EDHS 2016 report stunting prevalence decreased by 12 percent (from 58 percent to 51 percent) between 2000 and 2005 and by an additional 14 percent to 44 percent between 2005 and 2011. The government has provided due attention to malnutrition vulnerable groups of society, particularly fewer than five children, but the problems are still unsolved especially in Arsi Zone [9] what the current malnutrition status is exactly is also unanswered question of the researcher and community.

The prevalence of malnutrition in Ethiopia especially regarding to the association to academic performance is relatively not well documented, even not specific to the regions, localities and residence so far and limited data is available in Asella area. Because of the Chronic malnutrition has been a persistent problem for young children in Sub-Saharan Africa it is very important to determine the nutritional status of the communities currently facing the problems. Therefore, the current research was focused mainly to determine the nutritional status of school children in selected projects to associate with school academic performance [5].

\section{Research Methodology}

\section{Study area and study population}

Projects based case studies and cross-sectional study design were applied between April 2016 to June 2016 to determine the prevalence and magnitude of malnutrition toward the different factors among the project children who ranged three to twelveyear age. Semi-structured questionnaire was used to collect data from 217 children paired with their mothers or parents. Both quantitative and qualitative methods were used in the analysis from the Lutheran Church child development project that's included 340 children currently and it is found in Asella town. Asella is in Oromia regional state and it includes 24 Woredas and well known in productivity called product rich area. The methods used for the quantitative analysis were descriptive statistics such as mean values and percentages, bivariate and multivariate analysis. Logistic regressions were applied to identify degree of determinant. Registered students in Lutheran child development project (between Age 3 to 12 years) were included except the students with medical problems. The analysis sought to identify both common patterns across all the sites as well as differences, and the underlying reasons according to the following themes: understanding of the concept of malnutrition and its causes; the roles of food security/wealth; caring practices and health-seeking behavior in explaining child malnutrition; and the influence of various policies/programmes on child malnutrition.

\section{Sampling and sample size determination}

A total of 384 sample size were determined using a single proportion formula by using $36.5 \%$ of prevalence of stunting in Oromia region [4], 95\% confidence interval (CI), marginal of error $5 \%$ and plus $10 \%$ non-response rate were considered to increase the sample size. A Z-value of 1.96 used at $95 \% \mathrm{CI}$ and $\mathrm{d}$ of $5 \%$.

\section{Operational definitions}

Anthropometry: Measurement of the variation of physical dimensions [10].

Stunting: A child was defined as stunted if the height for age index was found to be below -2 SD of the median of the standard curve. Severe stunting was diagnosed if it was below -3 SD [10].

Underweight: Refers to a deficit and is defined as underweight below the -2 SD from the NCHS/WHO reference of the median of the standard curve. A severely underweight was diagnosed if it was below $-3 \mathrm{SD}[11,12]$.

Wasting: Nutritional deficient state of recent onset related to sudden food deprivation or mal-absorption utilization of nutrients which results weight loss, weight-for-height below2SD from the NCHS/WHO median value. Severe wastage was diagnosed if it was below $-3 \mathrm{SD}$ [12].

School performance: is determined based on the final mark and ranks obtained comparing each other in class room. Following the criteria of the FDRE Ministry of Education, school performance determinant where be classified according the WHO academic performance classification standards and assessed by the marks scored by the students in the all year exam conducted by the school in project area because the examination and measurements were conducted by nearest school Lutheran Kindergarten and elementary school.

\section{Ethical considerations}

Before going to conduct the research, the proposal was approved by Arsi University Ethical and Research Review Committee through department of Food Science and Postharvest Technology. Supportive letter was made from college of Agriculture and Environmental Science which states about the objective of the study to child development project.

\section{Data Collection Procedure}

During data collection Height and weight were measured and recorded from the health screening program conducted in the project for their routine purpose. Age of children was obtained from the recorded secondary data of birth date of children in the project. At the same time dietary assessment were conducted by students of Food Science and Postharvest Technology department. Socio-demographic characteristics of family/guardian or care givers was obtained through semistructured questionnaire in local language by employed child development project Social and health workers in coordination with the support of project director. As recommended by WHO, 
evaluation of nutritional status in this report is based on a comparison of three indices for the children in this survey, with indices reported for a reference population of well-nourished children by WHO Multicenter Growth Reference Study Group in 2006.

The three indices (height-for-age, weight-for-height, and weightfor-age) are expressed as standard deviation units from the median for the reference group. Children who fall below minus two standard deviations (-2 SD) from the median of the reference population are regarded as moderately malnourished, while those who fall below minus three standard deviations (-3 SD) from the reference population median are considered severely malnourished. Marked differences, especially regarding heightfor-age and weight-for-age, are often seen between different subgroups of children within a country. Whereas, the remaining data including child medical assessment, anthropometric measurement and dietary assessment were conducted by health professional sponsored by Compassion International Ethiopia.

\section{Questionnaires and data quality management}

Structured questionnaire was prepared in English and translated into Afaan Oromoo language and retranslated back to English by language experts to increase measurement accuracy and for field work purpose. For conducting diet survey, a minimum of three to four days of intake is generally required for characterizing usual individual intake of food type using well-structured and 24 dietary recall questionnaires were prepared.

\section{Data analysis}

The data was analyzed with the help of SPSS (version-23) software to find out the correlation between academic status and the various factors associated with study group. Oneway analysis of variance (ANOVA) was used to study the significant difference between the samples with respect to studied parameters. After collection, all data were compiled and analyzed, and appropriate statistical tests were applied. $\mathrm{P}<0.05$ was considered as statistically significant. Binary logistic regression analyses were carried out, using the odds ratio (OR) to determine the strength of predictors toward malnutrition and associations between various socio-economic indicators and nutritional status. For statistical analysis, 95\% confidence interval and adjusted odd ratio was checked and the significance variables were taken as associated factors of malnutrition.

\section{Result and Discussion}

\section{Socio-demographic characteristics of children and their parents/guardian}

Out of 384 children sample source to be included in this study from January to June 6/2017, about 217 (56.6\% response rate) children were included in the final analysis making response rate of $53.0 \%$. From the total 217 actively participated children, $98(45.3 \%)$ was males and $119(55.7 \%)$ were female. According to age group $100(46.15 \%)$ were aged between three to five. $102(47.0 \%)$ were age between $6-8$ and $8(6.84 \%)$ were between 9-12 age regarding the score of the children (Table 1).

In the school, $133(61.28 \%)$ of the children were in the moderately good while only $13(5.98 \%)$ of them was extremely strong academically in school performance. From the socio- demographic characteristics and dietary assessment of the parents/guardians, $75.21 \%$ of the guardians were prepared their own meal and $34(15.38 \%)$ of them were prepared their meal sometimes accordingly to their children's. Regarding to the monthly income assessment only $13.67 \%$ of them was earned 451 to 600 Ethiopian Birr. The educational status of the children's parents' those whose read and write was accounted for $147(67.52 \%)$ and the left $71(32.47 \%)$ were illiterate, whereas, from their marital status $78(35.89 \%)$ was divorced and $26.5 \%$ were single.

\section{Medical examination and status of the children}

The year of medical screening or examination for the children was conducted and reported below in Table 2. According to the result obtained almost all $(100 \%)$ of the children of the project were examined (Health Screened) annually once. From the clinical examination of physician during medical checkup $83.76 \%$ of the children was not malnourished and only $9.40 \%$ of them were moderately malnourished according to the case study of the children. From the test of diphtheria tetanus $70.94 \%$ of the children were not taken the vaccination and $29.06 \%$ of them has taken the vaccination. And for influenza diseases $76.07 \%$ has not taken the vaccination and $23.0 \%$ of them were taken, and for hepatitis A almost $100 \%$ of the children has not taken the vaccination. For hepatitis B the percentage of the children's whose took was $47.0 \%$ and $53.0 \%$ of them has not taken the vaccine.

\section{Dietary habits of children and parents/guardian including}

The dietary habits of the parents were presented in Table 3 below and $53.0 \%$ the people has consumed their food about usual and $47.0 \%$ of them was consumed less than usual. Dietary habits of children's and their parents were presented in Table 4 below. According to the result those children and parents was consumed potato, cabbage and carrot was $43.6 \%, 26.49 \%$ and $14.53 \%$ respectively. According to their food frequency responded during data collection they consumed three times per week for the maximum value of $33.33 \%$ and $28.2 \%$ of them do not consume fruits. And for meat consumption and frequency they consumed meat $7.69 \%$ where $76.93 \%$ did not consumed regularly per week.

\section{The nutritional status (wasting, stunting and malnutrition) of the children}

Regarding to the nutritional status of children based on WFA report of the Table 5 below, $88(40.17 \%)$ of children was categorized under moderately malnourished followed by $19.66 \%$ of severely malnourished children. While only about (33) $15.38 \%$ of them were free from the risk of malnutrition. From the HFA report 159 (73.5\%) of the school aged children was under a risk of stunting. Whereas, 131 (60.68\%) of children has not received vitamin A supplementation regularly within six months.

Factors associated with malnutrition (underweight, wasting and stunting) among school aged children between three to twelve in the Asella Lutheran Project

Results from the logistic regression of nutritional status of 
Table 1. Socio-demographic characteristics of children and their parents/guardian.

\begin{tabular}{|c|c|c|c|c|}
\hline \multicolumn{2}{|c|}{ Socio-demographic characteristics of children and their parents/guardian } & \multirow{2}{*}{$\begin{array}{c}\text { Frequency } \\
98\end{array}$} & \multirow{2}{*}{$\begin{array}{c}\text { Percentage } \\
45.3\end{array}$} & \multirow{2}{*}{$\begin{array}{c}\text { Valid \% } \\
45.3\end{array}$} \\
\hline Gender of children & Male & & & \\
\hline & Female & 119 & 54.7 & 54.7 \\
\hline \multirow[b]{2}{*}{ Age of children } & 6 to 8 & 12 & 47 & 47 \\
\hline & 9 to 12 & 15 & 6.84 & 6.84 \\
\hline \multirow{4}{*}{ School performance } & Extremely strong & 13 & 5.98 & 5.98 \\
\hline & Academically strong & 69 & 31.62 & 31.62 \\
\hline & Moderately good & 43 & 19.66 & 19.66 \\
\hline & Academically lower & 92 & 42.74 & 42.74 \\
\hline \multirow{3}{*}{$\begin{array}{l}\text { The one who prepare food } \\
\text { in home }\end{array}$} & Yes & 163 & 75.21 & 75.21 \\
\hline & No & 21 & 9.4 & 9.4 \\
\hline & Sometimes & 33 & 15.38 & 15.38 \\
\hline \multirow{3}{*}{ Monthly income of family } & Between 300-450 & 115 & 52.99 & 52.99 \\
\hline & Between 451-600 & 30 & 13.67 & 13.67 \\
\hline & Between 601-750 & 72 & 33.33 & 33.33 \\
\hline \multirow{2}{*}{$\begin{array}{l}\text { Educational status of } \\
\text { parents }\end{array}$} & Illiterate & 71 & 32.47 & 32.47 \\
\hline & Read and write & 146 & 67.52 & 67.52 \\
\hline \multirow{4}{*}{$\begin{array}{l}\text { Marital status of the } \\
\text { parents }\end{array}$} & Married & 11 & 5.13 & 5.13 \\
\hline & Single & 58 & 26.5 & 26.5 \\
\hline & Divorced & 78 & 35.89 & 35.89 \\
\hline & Separated by death & 70 & 32.47 & 32.47 \\
\hline \multirow{3}{*}{ Religion of the guardian } & Christian orthodox & 78 & 35.89 & 35.89 \\
\hline & Muslim & 54 & 24.79 & 24.79 \\
\hline & Christian protestant & 85 & 39.32 & 39.32 \\
\hline
\end{tabular}

Table 2. Medical status of the children.

\begin{tabular}{|c|c|c|c|c|}
\hline \multicolumn{2}{|c|}{ Medical status of the children's } & \multirow{2}{*}{$\begin{array}{c}\text { Frequency } \\
217\end{array}$} & \multirow{2}{*}{$\begin{array}{c}\text { Percent } \\
100\end{array}$} & \multirow{2}{*}{$\begin{array}{c}\text { Valid percent } \\
100\end{array}$} \\
\hline Year of medical screening/examination & 2017 & & & \\
\hline \multirow{3}{*}{$\begin{array}{l}\text { Malnourished status during the } \\
\text { examination according to the clinical } \\
\text { observation }\end{array}$} & No & 181 & 83.76 & 83.76 \\
\hline & Mild & 15 & 6.84 & 6.84 \\
\hline & Moderate & 21 & 9.4 & 9.4 \\
\hline \multirow{2}{*}{ Diphtheria Tetanus } & $\begin{array}{l}\text { Has NOT taken the vaccination } \\
\text { Diphtheria Tetanus }\end{array}$ & 154 & 70.94 & 70.94 \\
\hline & $\begin{array}{c}\text { Has taken the vaccination of Diphtheria } \\
\text { Tetanus }\end{array}$ & 63 & 29.06 & 29.06 \\
\hline \multirow[t]{2}{*}{ Influenza } & $\begin{array}{l}\text { Has NOT taken the vaccination of } \\
\text { Influenza }\end{array}$ & 165 & 76.07 & 76.07 \\
\hline & Has taken the vaccination of Influenza & 52 & 23.93 & 23.93 \\
\hline Hepatitis A & $\begin{array}{c}\text { Has NOT taken the vaccination of } \\
\text { Diphtheria Tetanus }\end{array}$ & 217 & 100 & 100 \\
\hline \multirow[t]{2}{*}{ Hepatitis B } & $\begin{array}{l}\text { Has not taken the vaccination of } \\
\text { Hepatitis B }\end{array}$ & 102 & 47 & 47 \\
\hline & Has taken the vaccination ofHepatitis B & 115 & 53 & 53 \\
\hline \multicolumn{2}{|c|}{ Total } & 217 & 100 & 100 \\
\hline
\end{tabular}

school aged children as shown in the Table 6 among the school aged children Female children were 1.105 times $(\mathrm{AOR}=1.105$, 95\% CI: 0.496-2.461) more likely to be malnourished than male school aged children. Where as in the factors associated with malnutrition of school aged children the odd ratio (OR) of a child going to be malnourished for completed supplementation of Vitamin A versus not completed supplementation of vitamin $\mathrm{A}$ is 1.298 ( $\mathrm{AOR}=1.298, \mathrm{CI}: 0.78$ and 2.156).

Therefore, children's whose did not completed supplementation of Vitamin A were 1.298 times (AOR=1.298, 95\% CI: 0.464-
3.601) more likely to be malnourished than children whose completed supplementation of Vitamin A regularly for six months. Regarding risk estimate among malnourished children who's not regularly vitamin A supplemented was 1.229 times (AOR: $1.229,95 \%$ CI: 0.534-2.828) more likely than children whose completed supplementation of Vitamin A within six months.

However, according to the finding among the children whose completed different vaccine supplementation was 0.379 times ( $\mathrm{AOR}=0.379,95 \% \mathrm{CI}: 0.17-0.848)$ less likely malnourished and in addition to that the risk estimate 0.742 times (AOR: 
Table 3. Dietary habits of guardian/children's.

\begin{tabular}{|c|c|c|c|c|}
\hline \multicolumn{2}{|c|}{ Socio-demography and the dietary habits of guardian/children's } & \multirow{2}{*}{$\begin{array}{c}\text { Frequency } \\
124\end{array}$} & \multirow{2}{*}{$\begin{array}{c}\text { Percent \% } \\
57.26\end{array}$} & \multirow{2}{*}{$\begin{array}{c}\text { Valid percent } \\
57.26\end{array}$} \\
\hline & Food prepared with salt of unknown source & & & \\
\hline Methods of preparing food type and additives & Preparing food by using iodized salt & 93 & 44.44 & 44.44 \\
\hline \multirow{2}{*}{ Amount of food consumed within 24 hours } & Usual & 115 & 53 & 53 \\
\hline & Less than usual & 102 & 47 & 47 \\
\hline \multirow{2}{*}{ Reason behind the consumption to be less than usual } & Sickness & 39 & 17.95 & 17.95 \\
\hline & Shortage of money & 178 & 82 & 82 \\
\hline
\end{tabular}

Table 4. Socio-demographics and the dietary habits of guardian/children's.

\begin{tabular}{|c|c|c|c|c|}
\hline \multicolumn{2}{|c|}{ Socio-demography and the dietary habits of guardian/children's } & \multirow{2}{*}{$\begin{array}{c}\text { Frequency } \\
184\end{array}$} & \multirow{2}{*}{$\begin{array}{c}\text { Percent \% } \\
84.62\end{array}$} & \multirow{2}{*}{$\begin{array}{c}\text { Valid percent } \\
84.62\end{array}$} \\
\hline & No especial diet and they will eat ever things & & & \\
\hline 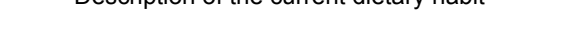 & Sometimes (per month meat \& variety) & 33 & 15.38 & 15.38 \\
\hline \multirow{4}{*}{ Type of food Consumed within week } & Cabbage & 58 & 26.49 & 26.49 \\
\hline & Carrot & 32 & 14.53 & 14.53 \\
\hline & Potato & 95 & 43.6 & 43.6 \\
\hline & Others & 32 & 15.38 & 15.38 \\
\hline \multirow{4}{*}{ Frequency of variety food consumed per week } & Once per week & 9 & 4.27 & 4.27 \\
\hline & Twice per week & 85 & 39 & 39 \\
\hline & Three times per week & 73 & 33.33 & 33.33 \\
\hline & Four times per week & 50 & 20.52 & 20.52 \\
\hline \multirow{4}{*}{ Fruit consumption (Banana, Orange, Avocado, etc.) } & No consumption per week as an opportunity & 62 & 28.2 & 28.2 \\
\hline & Once per week & 96 & 44.44 & 44.44 \\
\hline & Once per month & 58 & 26.49 & 26.49 \\
\hline & Twice per month & 1 & 0.9 & 0.9 \\
\hline \multirow{3}{*}{ Diary product consumption per week } & No & 141 & 64.96 & 64.96 \\
\hline & Once per week & 37 & 17.09 & 17.09 \\
\hline & Twice per week & 39 & 17.95 & 17.95 \\
\hline \multirow{3}{*}{ Meat consumed per week } & Yes & 17 & 7.69 & 7.69 \\
\hline & No & 167 & 76.93 & 76.93 \\
\hline & Sometimes as opportunities & 33 & 15.38 & 15.38 \\
\hline \multirow{3}{*}{ Meat consumption frequency } & No & 167 & 76.83 & 76.83 \\
\hline & Once per week & 15 & 6.84 & 6.84 \\
\hline & Not known & 35 & 16.24 & 16.24 \\
\hline \multirow{3}{*}{ Consuming of egg } & No & 165 & 76.07 & 76.07 \\
\hline & Once per week & 19 & 8.54 & 8.54 \\
\hline & Not known & 33 & 15.38 & 15.38 \\
\hline \multicolumn{2}{|c|}{ Total } & 217 & 100 & 100 \\
\hline
\end{tabular}

0.742, 95\% CI: $0.573-0.962$ ) less likely to be malnourished than children completed different vaccine supplementation. Regarding to the breakfast consumption based on the Table 6 children's who's not consumed their breakfast both some days and at the date of data collection was 38.37 times (AOR: 38.37, 95\% CI:12.51-117.69) more likely occurred malnutrition than children's whose consumed their breakfast all the time and also has took during data collection. 
Table 5. The nutritional status (wasting, stunting and malnutrition) of the children.

\begin{tabular}{|c|c|c|c|}
\hline Description & Frequency & Percentage & Valid \% \\
\hline \multicolumn{4}{|c|}{ Weight for age } \\
\hline WFA percentile $90-109 \%$ (normal) & 33 & 15.38 & 15.38 \\
\hline WFA percentile $75-89 \%$ (mild underweight) & 54 & 24.79 & 24.79 \\
\hline WFA percentile $60-74$ (moderately underweight) & 88 & 40.17 & 40.17 \\
\hline WFA percentile $<60 \%$ (severe underweight) & 42 & 19.66 & 19.66 \\
\hline \multicolumn{4}{|c|}{ Height for age } \\
\hline HFA $>95 \%$ Non-stunted & 58 & 26.5 & 26.5 \\
\hline HFA $<95 \%$ first degree stunting & 54 & 24.79 & 24.79 \\
\hline HFA $<90 \%$ second degree stunting & 63 & 29.06 & 29.06 \\
\hline HFA $<85 \%$ third degree stunting & 42 & 19.66 & 19.66 \\
\hline \multicolumn{4}{|c|}{ Weight for Height } \\
\hline WFH $>90 \%$ (Normal) & 85 & 39.32 & 39.32 \\
\hline WFH>85\% (Mild Wasting) & 68 & 30.77 & 30.77 \\
\hline WFH $>75 \%$ (Moderate Wasting) & 36 & 16.23 & 16.23 \\
\hline WFH<75\% (Severe Wasting) & 28 & 13.67 & 13.67 \\
\hline \multicolumn{4}{|c|}{ Supplementation of vitamin A } \\
\hline Received during the project & 22 & 10.26 & 10.26 \\
\hline Received without project entry & 21 & 9.4 & 9.4 \\
\hline Received but date is not unknown & 43 & 19.66 & 19.66 \\
\hline Not taken yet anywhere & 131 & 60.68 & 60.68 \\
\hline
\end{tabular}

Table 6. Factors associated with malnutrition status among school aged children between three to twelve, Asella Lutheran Project.

\begin{tabular}{|c|c|c|c|c|c|c|c|c|}
\hline \multirow{2}{*}{$\begin{array}{l}\text { Factors Associated with } \\
\text { Malnutrition }\end{array}$} & \multirow{2}{*}{ Characteristics } & \multicolumn{2}{|c|}{ Presence of Malnutrition } & \multirow{2}{*}{ AOR } & \multirow{2}{*}{$(95 \%, \mathrm{Cl})$} & \multirow{2}{*}{$\begin{array}{l}\text { Relative } \\
\text { Risk }\end{array}$} & \multirow{2}{*}{$(95 \%, \mathrm{Cl})$} & \multirow{2}{*}{ Sig. } \\
\hline & & No & Yes & & & & & \\
\hline \multirow{2}{*}{$\begin{array}{l}\text { Supplementation of Vitamin A } \\
\text { completed }\end{array}$} & No & $120 a$ & $52 a$ & 1.292 & $0.464-3.601$ & 1.229 & $0.534-2.828$ & 0.414 \\
\hline & Yes & $34 a$ & $11 a$ & 1 & & 1 & & \\
\hline \multirow{2}{*}{ Gender } & Female & $85 a$ & $34 a$ & 1.105 & $0.496-2.461$ & 1.03 & $0.815-1.301$ & 0.483 \\
\hline & Male & $68 a$ & $47 a$ & 1 & & 1 & & \\
\hline \multirow{2}{*}{ Completion of Immunization } & Yes & $78 a$ & $32 a$ & 1.024 & $0.461-2.276$ & 1.007 & $0.799-1.27$ & 0.557 \\
\hline & No & $75 a$ & $32 a$ & 1 & & 1 & & \\
\hline \multirow{2}{*}{ Registered Academic Grade Level } & Top Score & $48 a$ & $17 a$ & 1.267 & $0.519-3.092$ & 1.069 & $0.839-1.361$ & 0.387 \\
\hline & Low Score & $106 a$ & $46 a$ & 1 & & 1 & & \\
\hline \multirow{2}{*}{$\begin{array}{c}\text { Completion of Vaccine (BCG, } \\
\text { DPT, DT, MEN, FLU, MEA, PO, } \\
\text { PCV, HAE, HAB, HIA, HPV and } \\
\text { TT) }\end{array}$} & Yes & $58 a$ & $41 \mathrm{~b}$ & 0.379 & $0.17-0.848$ & 0.742 & $0.573-0.962$ & 0.014 \\
\hline & No & $96 a$ & $22 b$ & 1 & & 1 & & \\
\hline \multirow{2}{*}{ Consumption of Breakfast } & No & $137 a$ & $11 \mathrm{~b}$ & 38.37 & $12.51-117.693$ & 3.803 & $2.147-6.736$ & 0 \\
\hline & Yes & $17 a$ & $52 \mathrm{~b}$ & 1 & & 1 & & \\
\hline
\end{tabular}

Each subscript letter denotes a subset of Malnutrition Presence categories whose column proportions do not differ significantly from each other at the .05 level.

BCG: Bacillus Chalmette Guerin, DPT: Diphtheria Pertussis Tetanus, DT: Diphtheria Tetanus, MEN: Meningitis, FLU: Influenza, MEA: Measles, PO: Polio, PCV: Pneumococcal Conjugate Vaccine, HAE: Hepatitis A, HAB: Hepatitis B, HIA: H. Influenza Type B, HPV: Human Papilloma Virus and TT: Tetanus Toxoid

Regarding the Weight for Age (WFA), under nutrition assessment of the children based on the Table 7; female school aged children were 2.533 times $(\mathrm{AOR}=2.533,95 \% \mathrm{CI}: 1.17$ 5.487) more likely underweight than male school children in the project. Again, Relative risk were 1.767 (95\% CI: 1.078-2.894) times more than male children. From the maternal education/ guardians non-educated were 1.126 times $(\mathrm{AOR}=1.126,95 \%$ CI: 0.513-2.473) more developed under nutrition than formally educated mothers/guardians. In addition to all among the children whose consumed their breakfast during the period of data collection were also 0.118 times $(\mathrm{AOR}=0.118)$ less occurred under nutrition than whose did not consumed their breakfast. Whereas the risk factors associated with undernutrition were explained as children those not consumed their breakfast was 6
5.859 times $(\mathrm{AOR}=5.859,95 \% \mathrm{CI}: 2.235-15.362)$ more likely than children's whose consumed their breakfast.

From the Table 8 both the logistic regression and cross tabulation analysis predicted that Female school aged children was 1.112 times ( $\mathrm{AOR}=1.112,95 \% \mathrm{CI}$ : 0.504-2.454) more likely wasted compared with male school aged children included in the project. In the same manner children's who's not completed supplementation of vitamin A were 1.206 times (AOR=1.206, 95\% CI: 0.313-2.196) more likely wasted compared with children's whose completed supplementation of vitamin A. Regarding the completion of Immunization also had the closer determinant factor with 1.295 times $(\mathrm{AOR}=1.295,95 \% \mathrm{CI}$ : 0.58-2.893) more likely wasted than children whose completed 
Table 7. Factors associated with under nutrition status among school aged children between three to twelve, Asella Lutheran Project.

\begin{tabular}{|c|c|c|c|c|c|c|c|c|}
\hline \multirow{2}{*}{$\begin{array}{l}\text { Factors Associated with } \\
\text { Malnutrition }\end{array}$} & \multirow{2}{*}{ Characteristics } & \multicolumn{2}{|c|}{ WFA Underweight } & \multirow{2}{*}{ AOR } & \multirow{2}{*}{$(95 \%, \mathrm{Cl})$} & \multirow{2}{*}{ Relative Risk } & \multirow{2}{*}{$(95 \%, \mathrm{Cl})$} & \multirow{2}{*}{ Sig. } \\
\hline & & No & Yes & & & & & \\
\hline \multirow{2}{*}{$\begin{array}{l}\text { Supplementation of Vitamin A } \\
\text { completed }\end{array}$} & No & $76 a$ & $115 a$ & 0.882 & $0.285-2.729$ & 0.929 & $0.485-1.779$ & 0.523 \\
\hline & Yes & $11 a$ & $15 a$ & 1 & & 1 & & \\
\hline \multirow{2}{*}{ Gender } & Female & $59 a$ & $59 \mathrm{~b}$ & 2.533 & $1.17-5.487$ & 1.767 & $1.078-2.894$ & 0.014 \\
\hline & Male & $20 a$ & $71 \mathrm{~b}$ & 1 & & 1 & & \\
\hline \multirow{2}{*}{ Completion of Immunization } & Yes & $17 a$ & $45 a$ & 0.454 & $0.189-1.093$ & 0.603 & $0.329-1.104$ & 0.056 \\
\hline & No & $70 a$ & $85 a$ & 1 & & 1 & & \\
\hline \multirow{2}{*}{ Maternal/Guardian Education } & Illiterate & $29 a$ & $41 a$ & 1.126 & $0.513-2.473$ & 1.073 & $0.675-1.705$ & 0.46 \\
\hline & Educated & $57 a$ & $90 a$ & 1 & & 1 & & \\
\hline \multirow{2}{*}{$\begin{array}{c}\text { Completion of Vaccine (BCG, } \\
\text { DPT, DT, MEN, FLU, MEA, } \\
\text { PO, PCV, HAE, HAB, HIA, } \\
\text { HPV and TT) }\end{array}$} & Yes & $15 a$ & $35 a$ & 0.551 & $0.218-1.389$ & 0.684 & $0.365-1.281$ & 0.147 \\
\hline & No & $72 a$ & $95 a$ & 1 & & 1 & & \\
\hline \multirow{2}{*}{ Consumption of Breakfast } & Yes & $145 b$ & $41 \mathrm{~b}$ & 0.118 & $2.706-26.754$ & 0.17 & $2.235-15.362$ & 0 \\
\hline & No & $22 a$ & $12 a$ & 1 & & 1 & & \\
\hline
\end{tabular}

Each subscript letter denotes a subset of Malnutrition Presence categories whose column proportions do not differ significantly from each other at the .05 level.

BCG: Bacillus Chalmette Guerin, DPT: Diphtheria Pertussis Tetanus, DT: Diphtheria Tetanus, MEN: Meningitis, FLU: Influenza, MEA: Measles, PO: Polio, PCV: Pneumococcal Conjugate Vaccine, HAE: Hepatitis A, HAB: Hepatitis B, HIA: H. Influenza Type B, HPV: Human Papilloma Virus and TT: Tetanus Toxoid

Table 8. Factors associated with under nutrition status among school aged children between three to twelve, Asella Lutheran Project.

\begin{tabular}{|c|c|c|c|c|c|c|c|c|}
\hline \multirow{2}{*}{$\begin{array}{l}\text { Factors Associated with } \\
\text { Malnutrition }\end{array}$} & \multirow{2}{*}{ Characteristics } & \multicolumn{2}{|c|}{ WFH, Wasted } & \multirow{2}{*}{ AOR } & \multirow{2}{*}{$(95 \%, \mathrm{Cl})$} & \multirow{2}{*}{ Relative Risk } & \multirow{2}{*}{$(95 \%, \mathrm{Cl})$} & \multirow{2}{*}{ Sig. } \\
\hline & & No & Yes & & & & & \\
\hline \multirow{2}{*}{$\begin{array}{l}\text { Supplementation of Vitamin } \\
\text { A completed }\end{array}$} & No & $35 a$ & $13 a$ & 1.206 & $0.313-2.196$ & 1.056 & $0.723-1.242$ & 0.454 \\
\hline & Yes & $117 a$ & $52 a$ & 1 & & 1 & & \\
\hline \multirow{2}{*}{ Gender } & Female & $78 a$ & $32 a$ & 1.112 & $0.504-2.454$ & 1.032 & $0.814-1.308$ & 0.476 \\
\hline & Male & $73 a$ & $34 a$ & 1 & & 1 & & \\
\hline \multirow{2}{*}{ Completion of Immunization } & No & $82 a$ & $39 a$ & 1.295 & $0.58-2.893$ & 1.08 & $0.853-1.366$ & 0.335 \\
\hline & Yes & $70 a$ & $26 a$ & 1 & & 1 & & \\
\hline \multirow{2}{*}{$\begin{array}{l}\text { Maternal/Guardian } \\
\text { Education }\end{array}$} & Illiterate & $54 a$ & $46 a$ & 1.296 & $0.546-3.075$ & 1.078 & $0.846-1.373$ & 0.358 \\
\hline & Educated & $52 a$ & $19 a$ & & & & & \\
\hline \multirow{2}{*}{$\begin{array}{c}\text { Completion of Vaccine } \\
\text { (BCG, DPT, DT, MEN, FLU, } \\
\text { MEA, PO, PCV, HAE, HAB, } \\
\text { HIA, HPV and TT) }\end{array}$} & No & $37 a$ & $52 b$ & 12.4 & $4.703-32.695$ & 3.78 & $1.927-7.417$ & 0 \\
\hline & Yes & $115 a$ & $13 b$ & 1 & & 1 & & \\
\hline \multirow{2}{*}{ Consumption of Breakfast } & No & $30 a$ & $34 b$ & 17.556 & $5.238-58.833$ & 9.765 & $3.520-27.090$ & 0 \\
\hline & Yes & $7 a$ & $146 \mathrm{~b}$ & 1 & & 1 & & \\
\hline
\end{tabular}

Each subscript letter denotes a subset of Malnutrition Presence categories whose column proportions do not differ significantly from each other at the .05 level. BCG: Bacillus Chalmette Guerin, DPT: Diphtheria Pertussis Tetanus, DT: Diphtheria Tetanus, MEN: Meningitis, FLU: Influenza, MEA: Measles, PO: Polio, PCV: Pneumococcal Conjugate Vaccine, HAE: Hepatitis A, HAB: Hepatitis B, HIA: H. Influenza Type B, HPV: Human Papilloma Virus and TT: Tetanus Toxoid

immunization. In similar to that of under nutrition cases illiterate mothers/guardian's children also wasted 1.296 times ( $\mathrm{AOR}=1.296,95 \% \mathrm{CI}: 0.546-3.075)$ more likely than children's whose lived with formally educated guardians. Surprisingly, in the determinant factors of wasting status school aged children which does not completed different vaccination was 12.4 times (AOR=12.4, 95\% CI: 4.703-32.695) more likely wasted than children's whose completed vaccination during different medical treatment in the project life.

Regarding to the breakfast consumption determination due to wasting children's who's not consumed their breakfast both some days and at the date of data collection was 17.556 times (AOR: 17.556, 95\% CI: 5.238-58.833) more likely occurred malnutrition than children's whose consumed their breakfast all the time and also has took during data collection. The association to risk factors were 9.765 times (AOR=9.765, 95\%
CI: 3.520-27.090) more likely wasted than children who's not consumed their breakfast which was the risk factors to the health life were more explained and supported by Balvin Frantzenin in 2013 [11].

\section{Predictors for the malnutrition determinant (stunting, under-nutrition and wasting)}

According to the Table 9 regarding nutritional status, the prevalence of stunting (long duration malnutrition) was very high in comparison to the other nutritional status. Hence, the completion for supplementation of vitamin A does not categorize the strength of malnutrition in this result. Regression analysis were showed that female school children were 0.889 times $(\mathrm{AOR}=0.889,95 \% \mathrm{CI}: 0.428-1.85)$ less likely stunted than male school children in the project. 
Table 9. Factors associated with stunting among school aged children between three to twelve ages, Asella Lutheran Project.

\begin{tabular}{|c|c|c|c|c|c|c|c|c|}
\hline \multirow{2}{*}{$\begin{array}{c}\text { Factors Associated with } \\
\text { Malnutrition }\end{array}$} & \multirow{2}{*}{ Characteristics } & \multicolumn{2}{|c|}{ HFA, Stunted } & \multirow{2}{*}{ AOR } & \multirow{2}{*}{$(95 \%, \mathrm{Cl})$} & \multirow{2}{*}{ Relative Risk } & \multirow{2}{*}{$(95 \%, \mathrm{Cl})$} & \multirow{2}{*}{ Sig. } \\
\hline & & No & Yes & & & & & \\
\hline \multirow{2}{*}{$\begin{array}{l}\text { Supplementation of Vitamin A } \\
\text { completed }\end{array}$} & No & $63 a$ & $63 a$ & 1 & $0.473-2.113$ & 1 & $0.688-1.454$ & 0.576 \\
\hline & Yes & $46 a$ & $45 a$ & 1 & & 1 & & \\
\hline \multirow{2}{*}{ Gender } & Female & $61 a$ & $61 a$ & 0.889 & $0.428-1.847$ & 0.944 & $0.663-1.345$ & 0.449 \\
\hline & Male & $49 a$ & $46 a$ & 1 & & 1 & & \\
\hline \multirow{2}{*}{ Completion of Immunization } & Yes & $76 a$ & $72 a$ & 0.996 & $0.457-2.172$ & 0.998 & $0.683-1.459$ & 0.575 \\
\hline & No & $35 a$ & $34 a$ & 1 & & 1 & & \\
\hline \multirow{2}{*}{ Maternal/Guardian Education } & Educated & $39 a$ & $32 a$ & 1.267 & $0.583-2.755$ & 1.119 & $0.779-2.755$ & 0.345 \\
\hline & Illiterate & $72 a$ & $74 a$ & 1 & & 1 & & \\
\hline \multirow{2}{*}{$\begin{array}{c}\text { Completion of Vaccine (BCG, } \\
\text { DPT, DT, MEN, FLU, MEA, PO, } \\
\text { PCV, HAE, HAB, HIA, HPV and } \\
\text { TT) }\end{array}$} & Yes & $80 a$ & $59 a$ & 1.976 & $0.917-4.257$ & 1.416 & $0.935-2.146$ & 0.06 \\
\hline & No & $31 a$ & $47 a$ & 1 & & 1 & & \\
\hline \multirow{2}{*}{ Consumption of Breakfast } & No & $13 a$ & $50 a$ & 1.893 & $0.654-5.474$ & 1.709 & $0.709-4.118$ & 0.182 \\
\hline & Yes & $19 a$ & $135 a$ & & & & & \\
\hline
\end{tabular}

Each subscript letter denotes a subset of Malnutrition Presence categories whose column proportions do not differ significantly from each other at the .05 level.

BCG: Bacillus Chalmette Guerin, DPT: Diphtheria Pertussis Tetanus, DT: Diphtheria Tetanus, MEN: Meningitis, FLU: Influenza, MEA: Measles, PO: Polio, PCV: Pneumococcal Conjugate Vaccine, HAE: Hepatitis A, HAB: Hepatitis B, HIA: H. Influenza Type B, HPV: Human Papilloma Virus and TT: Tetanus Toxoid

Finally, the odd ratio for children's who's not consumed versus consumed breakfast was 1.893 and this was explained that students whose not consumed their breakfast also 1.893 times ( $\mathrm{AOR}=1.893$, 95\% CI: 0.654-5.474) more likely stunted than children's whose consumed their breakfast at the morning. The risk factors associated with this factors was 1.709 times (AOR=1.709, 95\% CI: 0.709-4.118) more likely under a risk to be stunted than whose consumed breakfast. But, no significant differences among the two group statistically $(\mathrm{p}=0.182)$.

\section{Discussion}

Generally, among the children were included in the project, $8.4 \%$ of the children was in the range of different categories of the malnutrition based on the weight and height assessment of the children. But, according to the data obtained from their case studies, the child project has given due attention to each of the children during the life of the project. From the result obtained the researcher found that more than $57 \%$ of children's in the projects were among the moderately good academically. There is an association between gender and nutritional status in the current finding in which supported by many scholars and contradict with study conducted in India [6]. But, there is no strong correlation between the school performance and the nutritional status of children for selected factors anywhere. From the regression and correlation between factors and dependent parameter none of them strongly predicted the dependent parameter and this might be due to physiological factors associated with the malnutrition of children were not explained.

From the WFA nutritional status determination, the percentages of the children's moderately malnourished was $40.17 \%$ and those of severely malnourished was around 19.66\%. Also, the HFA of the children were analyzed, and the non-stunted group of the children was around $26.50 \%$ while $29.06 \%$ of them were moderately stunted/second degree stunting (chronic malnutrition). Additionally, from the results obtained from the Z-score value it indicated that as $88.8 \%$ of the children were in normal condition of protein energy malnutrition (PEM) who's Z-score lies between -3 and -3SD). This data indicated that the explanation of Z-score also important that explaining 8 the malnutrition status of the children because extra $2.8 \%$ of the children malnutrition were occurred from the Z-score of them. However, in the reality Z-score cannot straightforward to explain to the public and difficult to explain clinical setting of the children.

Breakfast also makes a large contribution to daily micronutrient intake [11]. Consuming breakfast contribute to maintain BMI, have favorable nutrient intakes (Dietary fiber, total carbohydrate, low fat and cholesterol and up to $60 \%$ of water soluble vitamin and $\mathrm{Fe}$ ). Breakfast also associated with dietary lifestyle factors [12-15], also supported by Øverby and Høigaard [16]. Two cross-sectional studies in well-nourished adolescent populations reported a significant association between habitual breakfast consumption and behavior [16] found that frequency of breakfast was significantly associated with less self-reported disruptive behavior during lessons in adolescents (mean age 14.6 years) according the studies conducted currently in 2012 by Øverby and Høigaard [16].

As shown in Table 7 Maternal/guardians educational status was associated with children's underweight based on the current research. The report was consistent with previous other Ethiopian scholars finding at Bule Hora and in Bangladesh [1719]. The current finding was not consistent with EDHS in the 2016 survey [20]. The current cross sectional study showed that prevalence of child under nutrition, stunting and wasting was lower in the project comparing with the current status of Oromia region stunting prevalence as reported by EDHS 2016. The inconsistency might be due to small sample size compared to that of national data and the exclusion of children under the age of three years. The data showed only that $19.66 \%$ of children are considered short for their age or stunted (below-2 SD). In the current finding stunting is slightly higher among female than male children (i.e., $28.2 \%$ versus $20.5 \%$ ).

Weight-for-height describes current nutritional status. A child who is below -2 SD from the reference median for weight-forheight is considered too thin for his or her height, or wasted, a condition reflecting acute or recent nutritional deficits. Overall, $35(30 \%)$ of children in the project were under a risk of wasted (below -2 SD). Whereas the Weight-for-age is a composite index of weight-for-height and height-for- 
Citation: Elema TB. Predictors for the prevalence of under-nutrition, wasting and stunting of 3 to 12 years school aged children in the Asella Luther Child Development Project - Oromiyaa, Ethiopia.. J Nutr Hum Health. 2018;2(2):1-10

age and thus does not distinguish between acute malnutrition (wasting) and chronic malnutrition (stunting). Children can be underweighting for their age because they are stunted, wasted, or both. Weight-for-age is an overall indicator of a population's nutritional health. The results show that 40.17 percent of all children are underweight (below-2 SD), and 19.66 percent are severely underweight (below-3 SD). The highest percentages of underweight children are observed in the child development project and also the percentages were increased positively associated with decreasing parent's formal education, vitamin A supplementation and increasing of vaccine consumption.

\section{Conclusion}

From the study conducted within a short period among the school children of the Lutheran child development project 23 student was prevalence in severe underweight, 35 students were severely wasted and 23 was stunted based on the Weight for Age, Weight for Height and Height for age. But, in comparison to the current Oromia regional stunted students the prevalence of the malnutrition was occurred in less percent than the regional data of $2016[5,7,20]$. This all were supported by the regular medical treatment of the project at least annually. This might have helped students to keep their health and hearty life during project life.

\section{Recommendations}

The project should aware the family to give a balanced diet for their children's and there must be an attentive follow up of the project wither the children are on normal growth conditions or not. There must be supplementation for nutrients for the children under chronic level. Academic achievement of student is the ability of the student to study and remember facts and being able to communicate his knowledge orally or in written form even in an examination condition supported by Kpolovie [21]. Factors that influence students' academic achievement at primary school was also not conclusively known and could be multivariate in nature. They might include student's attitude towards school, interest in learning, study habit, attribution, selfefficacy, intelligence, and motivation [22]. Beyond students' perception of how well school will prepare them for life, their overall attitude to school and to all the school-related activities could be important. Breakfast is widely acknowledged to be the most important meal of the day and awareness creation also very important for the community to not miss breakfast possibly.

\section{Consent for Publication}

Not Applicable.

\section{Availability of Data and Materials}

Original data used for analysis were available and ready to be submitted in case of required.

\section{Competing Interests}

The authors declare that they have no competing interests.

\section{Funding}

The author does not receive any fund from the organization.

\section{Authors' Contributions}

The author, TBE was the principal investigator of the study and took the leading role from Conception, proposal writing, design and supervising the data collection process up to the final analysis and preparation of the manuscript.

\section{Acknowledgements}

I would like to acknowledge the parents of child development project for providing the valuable data during assessment. My sincere thanks go to Mr. Jemal Mohammed and the health workers of the project who's supported this research up to the final manuscript preparation. Special thanks also for Mr. Girma Negash Directors for the child development project and Lidya Mesfin for their cooperation, data collection and for giving us all the necessary information we demanded from the beginning up to the end of this work. Finally, author thank the study participants who willingly to took part in the study.

\section{References}

1. Glewwe P, Miguel EA. The impact of child health and nutrition on education in less developed countries. Handbook of Development Economics. 2007;4:3561-606.

2. Mengistu K, Alemu K, Destaw B. Prevalence of malnutrition and associated factors among children aged 6-59 months at Hidabu Abote District, North Shewa, Oromia Regional State. J Nutr Disorders Ther. 2013;1:1-5.

3. Ethiopian DHS. Central Statistical Agency, Addis Ababa, Ethiopia, October 2016;1:28-31.

4. Ethiopian DHS. Central Statistical Agency, Addis Ababa, Ethiopia, September 2006;1:19-20.

5. Alemu M, Nicola J, Belele T. Tackling child malnutrition in Ethiopia; Young lives project working paper No 19; Save the children UK-26. 2005.

6. Srivastava A, Mahmood SE, Srivastava PM, et al. Nutritional status of school-age children-A scenario of urban slums in India. Arch Public Health. 2012;70:1-8.

7. Ghosh S, Rakshit S, Bhattacharya M. Academic performance and nutritional status-A case study on college students in North Tripura. IOSR J Res Method Educ. 2013;1:57-68.

8. NNP, 2013. National Nutrition Program for the Government of the Federal Democratic Republic of Ethiopia. June 2013 - June 2015

9. National Nutrition Strategy Federal Ministry of Health, January 2008, Addis Ababa, Ethiopia.

10. http://www.who.int/childgrowth/standards/Technical_ report.pdf

11. Frantzen LB, Treviño RP, Echon RM, et al. Association between frequency of ready-to-eat cereal consumption, nutrient intakes, and body mass index in fourth-to sixthgrade low-income minority children. J Acad Nutr Diet. 2013;113:511-9.

12. Deshmukh-Taskar PR, Nicklas TA, O'Neil CE, et al. The relationship of breakfast skipping and type of breakfast consumption with nutrient intake and weight status in children and adolescents: The National Health and Nutrition Examination Survey 1999-2006. J Am Diet Assoc.2010;110:869-78. 
13. Gibson, S. Micronutrient intakes, micronutrient status and lipid profiles among young people consuming different amounts of breakfast cereals: Further analysis of data from the National Diet and Nutrition Survey of Young People aged 4 to 18 years. Public Health Nutr.2003;6:815-20.

14. De La Hunty A, Gibson S, Ashwell M. Does regular breakfast cereal consumption help children and adolescents stay slimmer? A systematic review and meta-analysis. Obes. Facts. 2013;6:70-85.

15. Szajewska H, Ruszczyński M. Systematic review demonstrating that breakfast consumption influences body weight outcomes in children and adolescents in Europe. Crit Rev Food Sci Nutr. 2010;50:113-9.

16. Øverby N, Høigaard R. Diet and behavioral problems at school in Norwegian adolescents. Food Nutr Res. 2012;56:17231.

17. Asfaw M, Wondaferash M, Taha M, et al. Prevalence of undernutrition and associated factors among children aged between six to fifty-nine months in Bule Hora district, South Ethiopia. BMC Public Health. 2015;15:41.
18. Amsalu S, Tigabu Z. Risk factors for severe acute malnutrition in children under the age of five. Ethiop $\mathrm{J}$ Health Dev. 2008;22:21-5.

19. Islam MM, Alam M, Tariquzaman M, et al. Predictors of the number of under-five malnourished children in Bangladesh: application of the generalized Poisson regression model. BMC Public Health. 2013;13:1-8.

20. NNP, 2016. National Nutrition Program for the Government of the Federal Democratic Republic of Ethiopia. June 2016 - June 2018.

21. Kpolovie PJ, Joe AI, Okoto T. Academic achievement prediction: Role of interest in learning and attitude towards school. International Journal of Humanities Social Sciences and Education (IJHSSE). 2014;1:73-100.

22. Kpolovie PJ. Effects of information processing styles and types of learning on students 'learning. Nigerian Journal of Empirical Studies in Psychology and Education (TNJGC). 2000;1:6-16.

\section{*Correspondence to:}

Teshome Bekele Elema

Department of Food Science and PHT

College of Agriculture and Environmental Sciences

Arsi University

Asella, Ethiopia

Tel: +251911543975

E-mail: elemabekele@gmail.com/teshome.bekele@ arsiun.edu.et 